\title{
QUÍMICA COM ANALOGIAS: O ESTUDO DA VIABILIDADE DE UM GUIA DIDÁTICO, A PARTIR DE REFLEXÕES DOCENTES
}

\author{
CHEMISTRY WITH ANALOGIES: THE STUDY OF THE FEASIBILITY OF A \\ TEACHING PROPOSAL, FROM TEACHING REFLECTIONS
}

\section{QUÍMICA CON ANALOGÍAS: EL ESTUDIO DE LA VIABILIDAD DE UNA GUÍA DIDÁCTICA, A PARTIR DE REFLEXIONES DOCENTES}

\author{
Rosiane Alexandre Pena Guimarães ${ }^{1}$ (D) 9 \\ Marcel Thiago Damasceno Ribeiro ${ }^{2}$ (D) 9
}

\begin{abstract}
RESUMO
O presente estudo apresenta a construção do Guia Didático intitulado Química com Analogias: guia com orientações para o uso de analogias no Ensino de Química, desenvolvido como parte do processo de uma investigação científica realizada junto ao Programa de Pós-Graduação de Ensino de Ciências Naturais (PPGECN) da Universidade Federal de Mato Grosso (UFMT). Objetiva-se com este contribuir para que professores de Química utilizem analogias como estratégia de ensino, em suas práticas pedagógicas, de forma consciente e sistematizada, a partir de subsídios teóricos e metodológicos, na busca de minimizar os obstáculos pedagógicos inerentes ao uso desse recurso. O método de estudo utilizado foi de abordagem qualitativa, pautada nas técnicas de Estudo de Caso. Como instrumentos de coleta de dados foram utilizados dois questionários e uma entrevista semiestruturada aplicados a seis professores, egressos do PPGECN/UFMT, campus Cuiabá, aprovados no Edital de Seleção de 2018 para área de Ensino de Química. A partir da análise da avaliação dos participantes foi possível concluir que o Guia Didático se apresenta como um material didático útil e viável, visto que os resultados foram satisfatórios e todos os sujeitos o aprovaram, em especial, quando informaram que o utilizariam no planejamento de suas aulas.
\end{abstract}

Palavras-chave: Analogias. Ensino de Química. Guia didático.

\begin{abstract}
The present study presents the construction of the didactic guide entitled Chemistry with Analogies: guide with guidelines for the use of analogies in the Teaching of Chemistry, developed as part of the process of a scientific investigation carried out with the Postgraduate Program of Teaching Natural Sciences (PPGECN) of the Federal University of Mato Grosso (UFMT). The objective is to contribute for Chemistry teachers to use analogies as a teaching strategy in their pedagogical practices, in a conscious and systematic way, based on theoretical and methodological subsidies, in the search to minimize the pedagogical obstacles inherent to the use of this resource. The study method used was a qualitative approach, based on the Case Study techniques. As instruments for data collection, two
\end{abstract}

\footnotetext{
${ }^{1}$ Mestra em Ensino de Ciências Naturais (PPGECN/UFMT), Professora da Educação Básica em Mato Grosso (SEDUC/MT). Endereço: Rua Cônego Guimarães, Quadra D, nº 15, bairro: Santa Izabel, Várzea Grande, Mato Grosso, Brasil, CEP:78.150-900. E-mail: rosianepena@hotmail.com.

${ }^{2}$ Pós-doutorando em Educação em Ciências e Matemática (PPGECM/UFG). Doutor em Educação em Ciências e Matemática (PPGECM/UFMT). Professor Adjunto III da Universidade Federal de Mato Grosso (UFMT). Endereço: Rua A, n. 107, Bloco A2, apto 32, Condomínio Cristal, bairro Terra Nova, Cuiabá, Mato Grosso, Brasil, CEP: 78.050-400. E-mail: marcel@ufmt.br.
} 
questionnaires and a semi-structured interview were applied to six teachers, graduates of PPGECN/UFMT, campus Cuiabá, approved in the selection notice of 2018 for the area of Teaching Chemistry. From the analysis of the participants' evaluation, it was possible to conclude that the didactic guide presents itself as a useful and viable didactic material, since the results were satisfactory and all subjects approved it, especially when they informed that they would use it in the planning of their classes.

Keywords: Analogies. Chemistry teaching. Didactic guide.

\section{RESUMEN}

El presente estudio presenta la construcción de la guía didáctica titulada Química con Analogías: guía con lineamientos para el uso de analogías en la Enseñanza de la Química, desarrollada como parte del proceso de una investigación científica realizada con el Programa de Posgrado de Docencia en Ciencias Naturales (PPGECN) de la Universidad Federal de Mato Grosso (UFMT). El objetivo es contribuir para que los profesores de Química utilicen las analogías como estrategia de enseñanza en sus prácticas pedagógicas, de manera consciente y sistemática, a partir de subsidios teóricos y metodológicos, en la búsqueda de minimizar los obstáculos pedagógicos inherentes al uso de este recurso. El método de estudio utilizado fue un enfoque cualitativo, basado en las técnicas de Estudio de Caso. Como instrumentos de recolección de datos, se aplicaron dos cuestionarios y una entrevista semiestructurada a seis docentes, egresados de PPGECN/UFMT, campus Cuiabá, aprobados en la convocatoria de selección de 2018 para el área de Docencia Química. Del análisis de la evaluación de los participantes se pudo concluir que la guía didáctica se presenta como un material didáctico útil y viable, ya que los resultados fueron satisfactorios y todos los sujetos la aprobaron, especialmente cuando informaron que la utilizarían en la planificación de sus clases.

Palabras clave: Analogías. Enseñanza de la química. Guía didáctico.

\section{INTRODUÇÃO}

Nas últimas décadas se notou um crescimento expressivo de estudos pertencentes à área de Ensino de Ciências Naturais, que abordam importantes discussões acerca de ações que se constituem como eficazes para o processo educativo. Diversos pesquisadores têm se preocupado em compreender como ocorre o processo de assimilação de conceitos, por parte dos estudantes, e para facilitar esse processo várias metodologias pedagógicas foram sugeridas ao longo desse período.

No Ensino de Ciências, diversos pesquisadores indicam que as analogias são um importante recurso didático (FERRAZ, 2006; RIGOLON; 2008; ALMEIDA, 2015), e que as analogias auxiliam o professor e os estudantes na compreensão de conceitos complexos e abstratos. O interesse por tal temática se justifica pelo fato de que as analogias fazem parte do processo cognitivo dos seres humanos e, ainda, se empregadas corretamente aproximam o estudante dos conceitos científicos, uma vez que lhes são apresentados conhecimentos novos e que podem causar estranhamentos. 
No Ensino de Química, por exemplo, uma Ciência que se caracteriza por apresentar uma linguagem própria para a representação do real, por meio de símbolos, de fórmulas, de convenções e de códigos, as analogias funcionam como facilitadoras da transição de conceitos abstratos para o concreto, tão importante no ensino dessa Ciência. Dessa forma, as analogias se constituem como um instrumento útil e eficaz no Ensino de Química, de modo a auxiliar a transposição do conceito do abstrato para um plano concreto (QUEIROZ, 2015).

Cabe ressaltar que as analogias não levam à substituição dos conceitos científicos no processo educativo, pelo contrário, ambas podem ser trabalhadas em conjunto, de forma que o método científico se mantém, a partir da linguagem científica e a simplificação da linguagem, por meio de analogias, favorecendo a construção da abstração, com base em algo que é familiar.

As analogias são uma forma atrativa, criativa, estimulante e eficaz de promover a abstração de conhecimentos científicos, devendo ser ativado o raciocínio analógico sempre que o assunto for distante da realidade, para que haja essa mediação entre os conhecimentos já estabelecidos e os que se encontram em construção (RIGOLON; OBARA, 2010).

A partir dessas considerações, o presente estudo teve o objetivo de verificar a viabilidade de um Guia Didático intitulado Química com Analogias: guia com orientações para o uso de analogias no Ensino de Química, desenvolvido como parte do processo de uma investigação científica realizada junto ao Programa de Pós-Graduação em Ensino de Ciências Naturais, que teve como problema de pesquisa: como contribuir para que professores de Química utilizem analogias como estratégia de ensino, em suas práticas pedagógicas, de forma consciente e sistematizada? O produto educacional, do tipo Guia Didático, foi construído com o objetivo geral de contribuir para que professores de Química utilizem analogias como estratégia de ensino, em suas práticas pedagógicas, de forma consciente e sistematizada, a partir de subsídios teóricos e metodológicos, em busca de minimizar os obstáculos pedagógicos inerentes ao uso desse recurso.

Para tanto, o presente estudo se encontra organizado em alguns tópicos, sendo esses: referencial teórico que fundamenta a função das analogias no Ensino de Ciências; a metodologia utilizada nesta investigação; a elaboração do Guia Didático; análises e resultados, em que se apresenta a avaliação do Guia Didático; as considerações em que são apresentadas as reflexões conclusivas acerca do estudo, seguidas das referências utilizadas. 


\section{ANALOGIAS E SUA FUNÇÃO NO PROCESSO EDUCATIVO}

É comum situações nas quais se faz necessário comparar aquilo que já se sabe com algo que se almeja conhecer, esse é um dos principais processos em que se atribui significado para a leitura de mundo e se adquire conhecimento. Por esse motivo, as analogias - comparações entre dois domínios, um ainda desconhecido (alvo), e outro já familiar (análogo) adotado como referência (FRANCISCO JÚNIOR, 2010) - desempenham um importante papel no desenvolvimento do conhecimento científico e podem ser poderosas ferramentas para a aprendizagem de Ciências.

\footnotetext{
As ciências constituem diversos campos do conhecimento alusivos às áreas de ensino e aprendizagem que recorrem, com frequência, ao uso de analogias e metáforas, pois, a partir desses mecanismos, há a possibilidade de construir, ilustrar ou compreender um domínio científico desconhecido a partir de um domínio familiar - que é o da comparação - com o intuito de se perceber uma conexão (LACERDA; BRITO, 2019, p. 165).
}

A ideia que permeia o campo das analogias é que essas envolvem o estabelecimento de comparações realizadas entre um domínio conceitual não familiar e um familiar, um observável e um não observável, um abstrato e um concreto, um desconhecido e um conhecido (FRANCISCO JÚNIOR, 2010). Assim sendo, as analogias figuram como ferramentas indispensáveis no auxílio da compreensão dos conceitos, que permeiam campos abstratos da Ciência, como no caso da Química, que ancora seus conceitos em uma perspectiva bastante abstrata, e surge como uma alternativa de ação na compreensão de conceitos científicos.

Os primeiros trabalhos, com interesses voltados ao estudo das analogias, surgiram na década de 1960. No entanto, somente na década de 1980 que as investigações nesse campo se intensificaram (OLIVA, 2008). Desde então, com o desenvolvimento das Ciências Cognitivas ${ }^{3}$, as investigações sobre analogias passaram a ter diferentes abordagens referentes ao seu papel no processo de ensino e aprendizagem (DUARTE, 2005).

É comum que ocorra certa confusão entre as analogias com outros tipos de recursos, como as metáforas, os modelos e o exemplo. Isso porque estão subordinados a ideia de comparação. Em se tratando do processo educativo é importante que os professores saibam diferenciar cada termo, para que assim as analogias sejam utilizadas corretamente em sala de aula (OLIVA, 2008).

\footnotetext{
${ }^{3}$ Campo multidisciplinar que integra desde a Psicologia, Filosofia da Ciência e Linguística até a Neurociência e Inteligência Artificial (DUARTE, 2005). 
Segundo Francisco Júnior (2010), caso a comparação seja implícita, ou seja, em que as relações entre os domínios não são claras, e salientam qualidades que não coincidem, nos dois domínios, se trata das metáforas; caso a comparação seja realizada entre conceitos que pertencem ao mesmo domínio se trata de exemplos; contudo, se a comparação utilizada for explícita, isto é, apresentam relações nítidas entre os domínios comparados, trata-se de analogias ou modelos.

Duarte (2005) afirma que, embora a palavra modelo tenha múltiplos significados, analogia não pode ser confundida com modelo, uma vez que corresponde a este uma representação de partes de estruturas do domínio alvo. Um modelo apresenta apenas uma visão ou cenário de um fragmento do todo. Normalmente, para estudar um determinado fenômeno complexo são criados vários modelos. Por exemplo, a analogia do Sistema Solar: pode-se ter uma ideia do átomo, não só por meio de comparações entre os dois domínios, mas a partir de modelos pictóricos como o proposto por Rutherford (RIGOLON, 2008). É interessante, ainda, considerar as analogias como comparações e os modelos como representações, para que não haja confusões.

Quando empregadas corretamente e sistematizadas, em um bom planejamento, as analogias são instrumentos úteis no Ensino de Ciências, como destaca Duarte (2005, p. 11), as analogias:

1. Levam à activação do raciocínio analógico, organizam a percepção, desenvolvem capacidades cognitivas como a criatividade e a tomada de decisões.

2. Tornam o conhecimento científico mais inteligível e plausível, facilitando a compreensão e visualização de conceitos abstractos, podendo promover o interesse dos alunos.

3. Constituem um instrumento poderoso e eficaz no processo de facilitar a evolução ou a mudança conceptual.

4. Permitem percepcionar, de uma forma mais evidente, eventuais concepções alternativas.

5. Podem ser usadas para avaliar o conhecimento e a compreensão dos alunos.

Assim, ao estabelecer comparações entre o análogo e o alvo, os estudantes fazem um levantamento e organizam as informações, de comparações e de hipóteses. Além disso, ao interpretarem um fenômeno, a partir da analogia, requerem que eles tenham atitudes críticas de testes de hipóteses, seleção das semelhanças mais evidentes e desconsideração de semelhanças superficiais. E ainda, a percepção e a imaginação são fundamentais na seleção de aspectos comuns a serem considerados. Dessa forma, as analogias podem ser motivadoras quando os estudantes se engajam e interagem com o assunto em estudo, em função da linguagem (analogia) ser mais familiar aos estudantes (FRANCISCO JÚNIOR, 2010). 
Embora o uso de analogias apresente várias vantagens para mediação do conhecimento, o seu emprego, sem os devidos cuidados, apresenta alguns riscos para a compreensão dos estudantes, principalmente, quando a abordagem se configura como prática de ensino espontânea, sem planejamento e com pouca reflexão por parte dos professores, o que pode levar a compreensão errônea de alguns conceitos.

É necessário que as analogias sejam utilizadas, de forma consciente, e para que isso aconteça é importante que os professores tenham conhecimento de alguns aspectos essenciais para o uso desse recurso em sala de aula. Entre os problemas quanto ao uso de analogias, no ensino, Duarte (2005, p. 12) destaca que:

1. A analogia pode ser interpretada como o conceito em estudo, ou dela serem apenas retidos os detalhes mais evidentes e apelativos, sem se chegar a atingir o que se pretendia;

2. Pode não ocorrer um raciocínio analógico que leve à compreensão da analogia;

3. A analogia pode não ser reconhecida como tal, não ficando explícita a sua utilidade;

4. Os alunos podem centrar-se nos aspectos positivos da analogia e desvalorizar as suas limitações.

A maioria dos problemas supracitados, conforme Mozzer e Justi (2013, p. 164) tem como causa:

a pouca familiaridade dos alunos com um determinado domínio base selecionado pelo professor; aspectos da estrutura do domínio base que podem gerar confusão por serem diferentes daqueles presentes na estrutura do alvo; transferência de concepções errôneas da base para o alvo.

Tais aspectos precisam ser considerados pelo professor ao utilizar analogias, em suas aulas, pois há diversas analogias que são amplamente utilizadas por professores no Ensino de Química. Uma receita de bolo pode ser usada para compreender a estequiometria. Unidades familiares como a dúzia ajudam os estudantes a entenderem os conceitos de mol. E ainda, analogias como bola de bilhar, pudim de passas, Sistema Solar para tornar os conceitos de Modelos Atômicos mais plausíveis.

Desse modo, ressalta-se a importância da orientação por parte dos professores no processo educativo, em que envolve o uso de analogias, pois se acredita que o sucesso desse processo está fortemente atrelado ao papel desempenhado pelos professores, no sentido de guiar os estudantes no estabelecimento das correspondências dos atributos do alvo e análogo.

Embora alguns autores acreditem que não usar analogias evita os obstáculos na aprendizagem, esse fato se mostra irreal, uma vez que se torna impossível dissociar o 
pensamento humano do uso de analogias para compreensão de algo (FRANCISCO JÚNIOR, 2010). Logo, os professores são predispostos a pensar analogicamente e, consequentemente, usam analogias em suas explicações.

A partir desses apontamentos, é de suma importância que os professores tenham clareza das vantagens e dos perigos das analogias para serem mais cuidadosos quando as utilizarem, espontaneamente, em suas aulas. Cabe destacar que o problema não está em o professor utilizar as analogias, em suas aulas, mas sim como é feito o uso dessas em suas aulas.

\section{METODOLOGIA}

Nesta seção são descritos o procedimento metodológico e os participantes da pesquisa. Nesse contexto, considerando a natureza desta pesquisa norteada pela questão: como contribuir para que professores de Química utilizem analogias como estratégia de ensino em suas práticas pedagógicas? Para elucidar o problema investigativo, a opção metodológica se alicerça nos pressupostos da abordagem qualitativa, a escolha por essa abordagem se justifica pela natureza dos dados, pois estes possuem enfoque textual ao invés de numérico e/ou estatístico, uma vez que essa abordagem, segundo Creswell (2010, p. 209), é "uma forma de investigação interpretativa em que os pesquisadores fazem uma interpretação do que enxergam, ouvem e entendem", com o pesquisador tipicamente envolvido em uma experiência intensiva com os sujeitos pesquisados. Assim sendo, na abordagem qualitativa se busca compreender as concepções, as atitudes e os comportamentos, a partir da perspectiva dos participantes da investigação (BOGDAN; BIKLEN, 1994), sendo esta uma importante característica para responder à questão de pesquisa supracitada.

Entre os diferentes métodos que a pesquisa qualitativa possui, para este estudo se optou pelo método de tipo Estudo de Caso, pois se trata de um método com viés focado no estudo de uma particularidade, no qual o pesquisador tem interesse em estudar um caso específico e permite com que se retenham as características holísticas e significativas dos eventos da vida real (YIN, 2015).

Desse modo, o caso em estudo foi a elaboração e a validação de Guia Didático, composto de orientações destinadas aos professores da Educação Básica quanto ao uso de analogias, em suas aulas, a fim de minimizar os obstáculos inerentes ao uso indiscriminado desse recurso. 
O instrumento de coleta de dados consistiu com a organização de dois questionários autoaplicáveis e uma entrevista semiestruturada. A escolha por esses instrumentos se justifica por apresentarem significativas possibilidades de investigação, que permitem conhecer e analisar melhor as opiniões e anseios dos sujeitos sobre o objeto analisado.

O questionário foi organizado na plataforma Google Formulários, e aplicado em dois momentos distintos da investigação. No primeiro momento foram elaboradas questões com o intuito de caracterizar os sujeitos e, também, identificar suas concepções sobre o uso de analogias como estratégia de ensino. No segundo momento, o questionário teve como objetivo avaliar o Guia Didático, elaborado como parte integrante da pesquisa educacional. Todos os questionários, juntamente com o convite e a carta de apresentação da pesquisa, foram enviados via e-mail, a fim de facilitar aos sujeitos e, possivelmente, deixá-los mais à vontade.

A entrevista semiestruturada se constituiu na tentativa de aprofundar as respostas dadas pelos sujeitos, por sua vez, foi organizada em dois blocos, sendo o primeiro composto por depoimentos sobre a atuação profissional, e o segundo com os depoimentos sobre as analogias como estratégia de ensino, em que os sujeitos tiveram a oportunidade de contar, espontaneamente, como ocorre o planejamento teórico, prático e estratégico ao ensinar os conceitos químicos com auxílio das analogias.

Participaram da pesquisa seis professores ${ }^{4}$, todos Licenciados em Química, que ministram aulas da disciplina de Química, em diferentes cidades, na rede pública de ensino do Estado de Mato Grosso. Com a autorização expressa e consentida, os professores responderam ao questionário e a entrevista. A escolha dos participantes decorre de serem estes egressos do PPGECN, cenário em que ocorreu a pesquisa, por atuarem e/ou já terem atuado na Educação Básica como professores de Química e por terem, em algum momento da docência, recorrido ao uso de analogias no ensino. Para preservar a identidade dos professores, esses foram denominados de: P1, P2, P3, P4, P5 e P6.

Para a análise dos registros de informações se recorreu à Análise Textual Discursiva (ATD), proposta por Moraes e Galiazzi (2011). A escolha pela ATD se deve por esta permitir uma análise rigorosa e síntese subsequente, a qual possibilita a construção de novos conhecimentos de forma a ampliar os significados do fenômeno pesquisado. De acordo com estes autores, a ATD é composta por três etapas fundamentais: a desmontagem dos textos (unitarização), o estabelecimento de relações (categorização) e captação do novo emergente

\footnotetext{
${ }^{4} \mathrm{O}$ resultado final do processo seletivo do PPGECN apresenta sete aprovados para área de concentração de ensino de Química, porém no decorrer do ano houve uma desistência, conferindo, assim, seis sujeitos. 
(metatexto). Com base nessas etapas, a "intenção é a compreensão, reconstruir conhecimentos existentes sobre os temas investigados" (MORAES; GALIAZZI, 2011, p.11).

Após a análise dos dados, foi elaborado o produto educacional ${ }^{5}$ do tipo Guia Didático com o intuito de suprir algumas necessidades encontradas e, a partir daí, foi avaliado com objetivo de identificar sua viabilidade no processo educativo.

\section{ELABORAÇÃO DO GUIA DIDÁTICO}

$\mathrm{O}$ uso das analogias, em ambiente de aprendizagem, requer orientações valiosas. $\mathrm{O}$ preparo do professor e o planejamento das analogias são essenciais para que seu uso resulte em uma construção adequada do conhecimento. Para que isso aconteça, os professores precisam adquirir: “[...] um conhecimento da teoria relacionada a esse tipo de recurso [...] bem como conhecimento das discussões sobre as vantagens e desvantagens das estratégias de ensino com analogias devem ser consideradas [...]" (FERRAZ; TERRAZZAN, 2002, p. 127).

Uma preocupação compartilhada em diversas pesquisas da área é que o uso das analogias acontece de maneira espontânea e sem nenhum planejamento por parte dos professores. Segundo Francisco Júnior (2010), os professores de Ciências não recebem nenhuma instrução formal de como usar esse recurso em suas aulas. Essa situação contribui para que o uso espontâneo permaneça, o que favorece para aprendizagem inadequada dos conceitos.

Oliva (2008) corrobora ao afirmar que é necessário que o professor se aproprie de dois saberes essenciais: o saber sobre as analogias e o saber fazer diante das analogias. Primeiramente, o professor precisa saber o que é uma analogia, o que a diferencia dos outros recursos, quais suas vantagens e desvantagens no processo educativo, os mecanismos de aprendizagem a partir de analogias, etc. Por seguinte, é necessário selecionar boas analogias, analisar suas limitações, propor atividades de elaboração e de aplicação.

A partir dessas considerações e da análise dos dados, foi elaborado um produto educacional intitulado: Química com analogias: guia didático com orientações para o uso de analogias no Ensino de Química, representado pela capa e contracapa na figura 01, que se configura como uma proposta didática com orientações, que podem auxiliar os professores quanto ao uso das analogias, em sala de aula, para que assim sejam utilizadas, de forma efetiva, no ensino de Ciências Naturais, em especial, no de Química.

$5 \mathrm{O}$ produto educacional tem livre acesso na página do PPGECN da UFMT no endereço eletrônico: https://fisica.ufmt.br/pgecn/ 


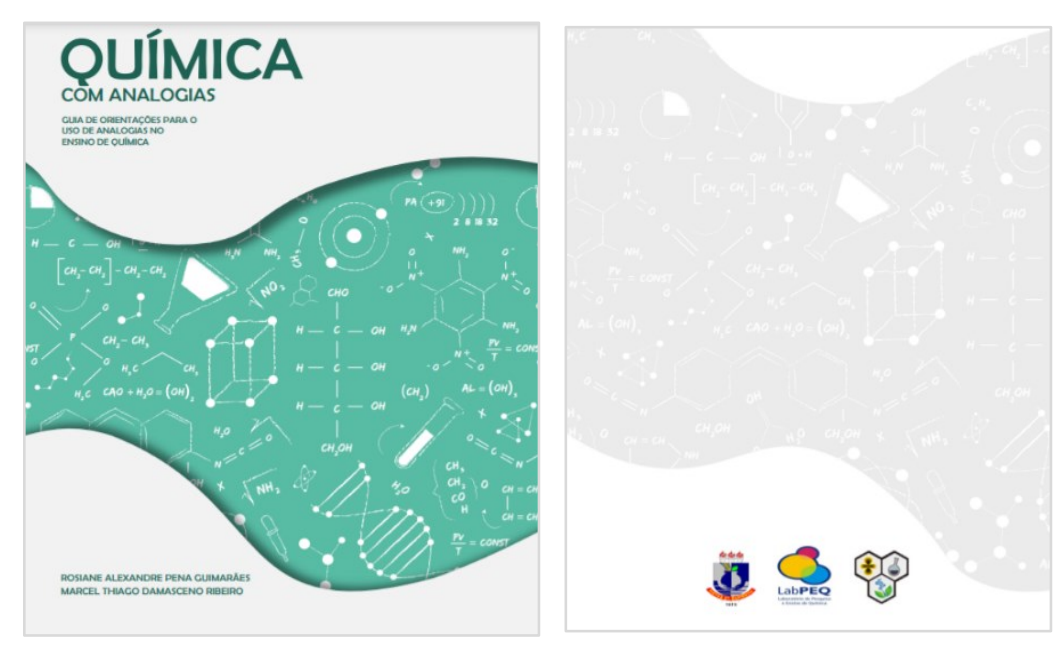

Figura 01: capa e contracapa do Produto Educacional. Fonte: elaboração dos autores (2020).

Com o intuito de viabilizar subsídios teóricos sobre analogia, o guia didático possui 38 páginas distribuídas em dois momentos. O primeiro apresenta informações quanto à definição das analogias, a diferença das analogias dos demais recursos, como as analogias se apresentam nos livros didáticos e, ainda, os critérios para classificação desse recurso, bem como os aspectos a serem considerados ao empregar uma analogia. O segundo momento se destina a apresentar algumas propostas de ensino com analogias: centradas no professor, centradas no estudante e, em ambos, por fim, expõe alguns exemplos de analogias utilizadas no ensino de conceitos químicos, bem como a aplicação dos modelos TWA e MECA ${ }^{6}$, a título de sugestão para duas dessas. A distribuição do conteúdo na proposta didática ocorre da seguinte maneira:

- Apresentação

- Introdução

- Professor, você sabe o que é analogia?

- Diferença entre analogias e outros recursos

- Analogias em livros didáticos

- Classificação das analogias

- Dicas para analogias mais eficazes

- Propostas de ensino com analogias

- Algumas analogias que podem ser usadas em conceitos químicos do Ensino Médio

- Últimas palavras...

\footnotetext{
${ }^{6}$ As siglas TWA e MECA correspondem respectivamente, Modelo Ensinando com Analogias, sendo a tradução do inglês, Teaching With Analogies - (TWA); e Modelo de Ensino com Analogias - (MECA).
} 
- Referências

Para subsidiar o Guia Didático, para além do conteúdo expresso, foi disponibilizada também uma área de sugestões de leitura, com endereços eletrônicos para o acesso a diferentes artigos sobre a temática e, assim, propiciar aos professores outras possibilidades e abordagens das analogias. A área atividades, ao final do Guia, possui algumas questões que levam o professor a refletir sobre o conteúdo abordado. Apresenta também à margem da página as chamadas: Atenção professor! Lembre-se! Você Sabia! que contêm informações adicionais sobre o assunto.

Em linhas gerais, o objetivo deste material é reunir informações orientativas que oportunizem a reflexão, no planejamento das aulas e/ou atividades, por meio de analogias, para que assim o seu uso aconteça, de forma efetiva, minimizando o máximo possível os obstáculos pedagógicos que possam surgir no processo educativo.

É importante ressaltar que o produto educacional foi elaborado com base nas perspectivas expressas pelos professores de Química, que atuam em diferentes escolas do Estado de Mato Grosso, porém esse material pode servir de apoio para formação inicial e continuada de professores da área das Ciências da Natureza (Química, Física e Biologia), uma vez que seus conceitos permeiam o campo da abstração, o que leva os professores fazerem uso de analogias.

\section{ANÁLISES E RESULTADOS}

\subsection{Avaliação da proposta didática}

Tendo em vista que a proposta didática intitulada: Química com analogias: guia didático com orientações para o uso de analogias no Ensino de Química foi desenvolvida a partir de informações, cujo objetivo é auxiliar os professores quanto ao uso das analogias em suas práticas pedagógicas, buscou-se subsídios para a criação de um instrumento de avaliação ${ }^{7}$. A avaliação do produto educacional ocorreu no mês de outubro de 2020, e foi realizada por cinco $^{8}$ sujeitos da pesquisa (P1, P2, P4, P5 e P6).

\footnotetext{
${ }^{7}$ A ficha de avaliação elaborada foi adaptada da bibliografia: Dal Pupo, Daiana. SUA NOVA MAJESTADE: A SOJA: Um paradidático como estratégia pedagógica para o ensino de Química em Mato Grosso. 2015. Dissertação de Mestrado.

${ }^{8}$ Dos seis sujeitos como descrito no percurso metodológico desta pesquisa, somente cinco retornaram a ficha avaliativa do produto educacional. 
A ficha de avaliação foi dividida em dois blocos, a saber: bloco I- avaliação dos aspectos técnicos do Guia, sendo esses: organização clara e coerente, adequação da linguagem, isenção de erros de revisão e/ou impressão, ilustrações, acesso a outras mídias e linguagem acessível; bloco II - constituído de cinco questões relacionadas ao uso do Guia Didático no planejamento das aulas e, por fim, um espaço para que os avaliadores deixassem seus comentários, sugestões ou críticas.

No total de seis itens (bloco I), os sujeitos tiveram a possibilidade de escolher apenas uma das cinco opções de respostas: Ótimo, Bom, Regular, Ruim e Péssimo. A figura 02 apresenta os resultados da avaliação dos aspectos técnicos, indicando o total de opções marcadas e os itens avaliados por cada sujeito da pesquisa.

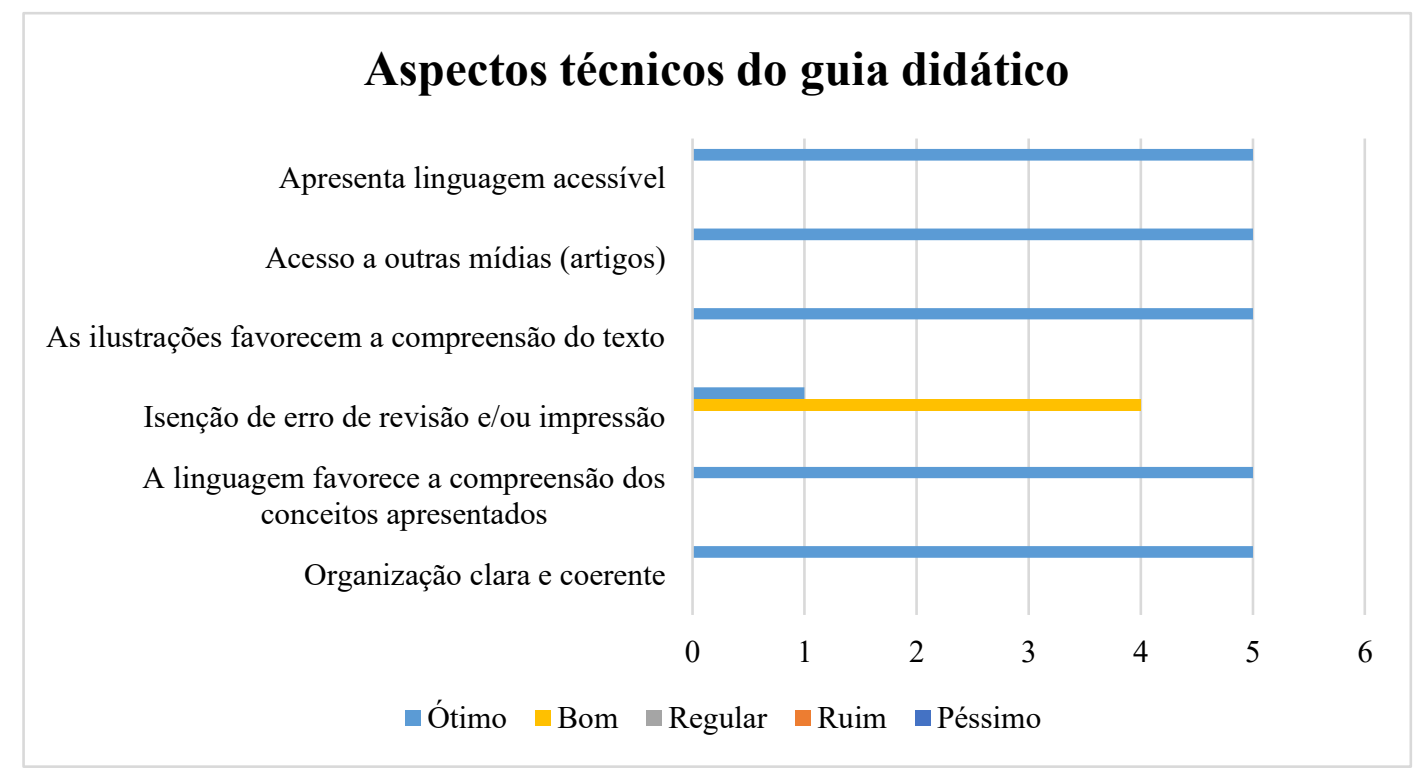

Figura 02: Aspectos técnicos do guia didático. Fonte: elaboração dos autores (2020).

Foram obtidas 26 avaliações ótimo e 4 bom. Para os itens ruim, regular e péssimo não houve atribuição. Nos itens organização clara e coerente, adequação da linguagem, as ilustrações favorecem a compreensão do texto, acesso a outras mídias e apresenta linguagem acessível, os cinco avaliadores consideraram como ótimo. Quanto ao item isenção de erro de revisão e/ou impressão, 1 avaliador considerou como ótimo e 4 avaliadores como bom.

Dessa forma, por meio do predomínio da opção ótimo se constatou que o Guia Didático atende aos aspectos técnicos na concepção dos professores, uma vez que eles possuem vivência com materiais da área. Esse fato teve grande relevância para a pesquisa, pois na construção do Guia Didático se teve a preocupação de elaborar um material, que atendesse aos requisitos técnicos, a fim de contribuir para o estudo com qualidade. 
No bloco II foram elaboradas questões que envolviam aspectos sobre a utilização do Guia Didático no planejamento das aulas. Nesse bloco, as cinco questões procuraram desvendar se a leitura contribuiu ou não para a (re)formulação das suas concepções quanto ao uso das analogias em suas aulas.

Na primeira questão desse bloco, os sujeitos tiveram duas opções de respostas: sim ou não, e em seguida deveriam tecer um comentário ao questionamento: você utilizaria o material: Química com analogias: guia didático com orientações para o uso de analogias no Ensino de Química no planejamento das atividades didático-pedagógicas que envolvem o uso de analogias? Todos os avaliadores responderam que sim. No entanto, após responder, os avaliadores tiveram a oportunidade de fazer um comentário referente a sua resposta, conforme apresentado no quadro 01 .

\begin{tabular}{|c|l|}
\hline Sujeitos & \multicolumn{1}{c|}{ Resposta/Comentário } \\
\hline $\mathbf{P 1}$ & $\begin{array}{l}\text { Sim. Utilizaria mais como um material de apoio para mim, para melhorar meus exemplos } \\
\text { e explicações. }\end{array}$ \\
\hline $\mathbf{P 2}$ & $\begin{array}{l}\text { Sim. O material favorece a compreensão do uso de analogias. Esclareceu muitas confusões } \\
\text { entre os termos: exemplos, analogias e metáforas. }\end{array}$ \\
\hline $\mathbf{P 4}$ & $\begin{array}{l}\text { Sim, pois o guia traz exemplos de analogias que já foram estudadas nos auxiliando a não } \\
\text { produzir um obstáculo epistemológico. }\end{array}$ \\
\hline $\mathbf{P 5}$ & $\begin{array}{l}\text { Sem dúvida, irei utilizar o guia no planejamento das minhas aulas, pois esse contém } \\
\text { informações que enriquecem e viabilizam o uso elou a construção de analogias com fins } \\
\text { didáticos-pedagógicos. Além disso, o material está muito bem estruturado, tanto em } \\
\text { conteúdo, quanto em diagramação e linguagem (a leitura é acessível e flui facilmente). }\end{array}$ \\
\hline & $\begin{array}{l}\text { Sim, para se trabalhar os conteúdos de Química entre outras da área de Ciências, em sala de } \\
\text { aula, oportunizando aos estudantes um ensino mais dinâmico, interativo e atrativo em meio } \\
\text { ao momento em que estamos vivendo durante a Pandemia. }\end{array}$ \\
\hline
\end{tabular}

Quadro 01: respostas dos avaliadores na questão 1.

Fonte: elaboração dos autores (2020).

A partir da apreciação dos sujeitos, é possível inferir que o Guia Didático pode ser utilizado como suporte aos professores no planejamento de suas atividades didáticopedagógicas, uma vez que os comentários dos avaliadores vêm ao encontro do objetivo do material, que é fornecer subsídios teóricos e metodológicos para auxiliar o professor quanto ao uso das analogias em suas aulas.

Na segunda questão do bloco, os sujeitos foram indagados: o material: Química com analogias: guia didático com orientações para o uso de analogias no Ensino de Química, ampliou e/ou reformulou suas concepções sobre as analogias como estratégia de ensino? Em seguida, comentar em qual sentido, conforme apresentado no quadro 02. 


\begin{tabular}{|c|c|}
\hline Sujeitos & Resposta/Comentário \\
\hline P1 & $\begin{array}{l}\text { Sim. No sentido de me importar mais em como o conhecimento está sendo construído no } \\
\text { pensamento do aluno. Não basta que ele aprenda, ele precisa entender o assunto com } \\
\text { profundidade e segurança. }\end{array}$ \\
\hline P2 & $\begin{array}{l}\text { Sim, principalmente, no que se refere às diferenças entre os termos exemplos, analogias e } \\
\text { metáforas e sobre os momentos ideias para usar essas ferramentas. }\end{array}$ \\
\hline P4 & $\begin{array}{l}\text { Sim, pois no guia além de explicar todo o conceito de analogia, auxilia o professor a criar } \\
\text { sua própria analogia e aplicá-la de forma correta. }\end{array}$ \\
\hline P5 & $\begin{array}{l}\text { Sim, pois não conhecia os diversos métodos apresentados e nem tinha tanta clareza em } \\
\text { distinguir metáfora de analogia. Ademais, ressignifiquei o modo como entendo a analogia } \\
\text { no ensino de Química, pois apesar de utilizá-las (mesmo que raramente), em sala de aula, } \\
\text { sempre ficava apreensivo quanto à possibilidade de os estudantes não as relacionar } \\
\text { corretamente com os conteúdos, ou ainda, produzir obstáculos à aprendizagem -- um risco } \\
\text { que pode ser minimizado se a analogia estiver coerentemente planejada com os objetivos } \\
\text { de aprendizagem (o que reforça a importância desse guia didático). }\end{array}$ \\
\hline P6 & $\begin{array}{l}\text { Sim. As analogias acompanham o meu percurso profissional desde o início de minha } \\
\text { carreira, em 1999, contudo, a compreensão sobre elas não era tão clara, desde que } \\
\text { utilizadas corretamente e com objetivo de facilitar a aprendizagem dos conceitos } \\
\text { científicos, promovendo assim um papel importante no processo de ensino e aprendizagem, } \\
\text { e este Guia potencializa e esclarece a compreensão sobre a importância de se trabalhar } \\
\text { com as analogias no ensino de Quimica. }\end{array}$ \\
\hline
\end{tabular}

Quadro 02: respostas dos avaliadores na questão 2

Fonte: elaboração dos autores (2020).

Para Vasconcelos (2011), materiais do tipo Guia Didático possibilitam ressignificar conceitos dos indivíduos. Para tal, o mesmo precisa estar estruturado e organizado, contemplar uma boa referência bibliográfica e de atividades a serem desenvolvidas no contexto escolar. $\mathrm{Na}$ elaboração do Guia Didático, a preocupação principal foi trazer informações, ideias, apontamentos e conteúdo de maneira clara e objetiva, que auxiliam na construção do conhecimento, na ressignificação dos conceitos e na conquista da autonomia quanto ao uso das analogias em sala de aula. Dessa forma, foi possível inferir que a proposta atende as características de um Guia Didático, uma vez que todos os avaliadores responderam que tiveram suas concepções ampliadas e/ou reformuladas após a leitura do material, esse fato revela um aspecto positivo para a proposta didática.

A terceira questão: as orientações presentes no guia contribuem para diminuição dos obstáculos à aprendizagem, ao trabalhar com analogias em suas aulas? Todos os avaliadores acreditam que as orientações apresentadas no Guia Didático diminuem os obstáculos que as analogias podem causar para a aprendizagem. As respostas dos avaliadores são apresentadas no quadro 03. 


\begin{tabular}{|c|c|}
\hline Sujeitos & Respostas \\
\hline P1 & $\begin{array}{l}\text { As orientações trazidas pelo material diminuem os obstáculos de aprendizagem quando } \\
\text { conscientizam o professor da estratégia de ensino que ele está utilizando. Essa percepção } \\
\text { de que o ensino deve ser ancorado em estratégias e não em "transmissão" ou "improvisos", } \\
\text { é muito carente aos professores. }\end{array}$ \\
\hline $\mathbf{P 2}$ & $\begin{array}{l}\text { Sim, além de esclarecer o sentido do uso das analogias, traz exemplos práticos sobre seu } \\
\text { uso. }\end{array}$ \\
\hline $\mathbf{P 4}$ & Sim, pois ao explicar o conceito de analogia e a forma que essa deve ser trabalhada. \\
\hline P5 & $\begin{array}{l}\text { Sim, especialmente pela possibilidade de estabelecer diretrizes para a construção e o uso } \\
\text { de analogias para o ensino-aprendizagem. }\end{array}$ \\
\hline P6 & $\begin{array}{l}\text { Com certeza é um material que servirá como recurso pedagógico para minimizar possíveis } \\
\text { obstáculos pedagógicos que surgem ao se trabalhar com analogias no ensino de Química, } \\
\text { podendo quebrar possiveis paradigmas oriundos da formação inicial acadêmica. }\end{array}$ \\
\hline
\end{tabular}

Quadro 03: respostas dos avaliadores na questão 3.

Fonte: elaboração dos autores (2020).

De acordo com P1, os obstáculos à aprendizagem são menores quando conscientizam o professor da estratégia que ele faz uso. Esse pensamento também é compartilhado por Ferraz e Terrazzan (2002), ao defenderem que ao ter conhecimentos relacionados ao uso das analogias, os professores terão condições de incluí-las, de forma estruturada, em seu planejamento, minimizando assim os obstáculos que podem surgir no processo educativo.

A quarta questão teve a finalidade de identificar o que mais despertou a atenção dos avaliadores no Guia Didático. As respostas são apresentadas no quadro 04.

\begin{tabular}{|c|c|}
\hline Sujeitos & Respostas \\
\hline P1 & $\begin{array}{l}\text { O tópico dicas para analogias mais eficazes é o que mais chamou minha atenção, pois ele } \\
\text { fala diretamente com a prática do professor e logo em seguida, no tópico propostas de } \\
\text { ensino com analogias sugere essa prática de forma mais detalhada. }\end{array}$ \\
\hline $\mathbf{P 2}$ & $\begin{array}{l}\text { Gostei de tudo, mas, o que mais chamou minha atenção foi a parte: diferença entre } \\
\text { analogias e outros recursos e algumas analogias que podem ser utilizadas em conceitos } \\
\text { químicos do Ensino Médio. }\end{array}$ \\
\hline $\mathbf{P 4}$ & O quadro de analogias que podem auxiliar os professores separado por ano. \\
\hline P5 & $\begin{array}{l}\text { As diferentes metodologias para se trabalhar com analogias no ensino de Química, como } \\
\text { um recurso que pode potencializar a aprendizagem. }\end{array}$ \\
\hline P6 & $\begin{array}{l}\text { É um material atrativo, dinâmico e muito didático. Material com grande sensibilidade } \\
\text { ilustrativa, fator essencial para que o leitor se sinta acolhido pelo texto e o objetivo do } \\
\text { material proposto no Guia orientativo. }\end{array}$ \\
\hline
\end{tabular}

Quadro 04: respostas dos avaliadores na questão 4.

Fonte: elaboração dos autores (2020).

De maneira geral, quase todos os tópicos despertaram a atenção de um avaliador específico. Assim, pode-se considerar que o Guia Didático dispõe de tópicos atrativos constituídos de informações relevantes para bom entendimento do papel das analogias no processo educativo.

A quinta questão teve a finalidade de investigar qual a opinião dos avaliadores em relação ao Guia Didático. O quadro 05 reúne os depoimentos de cada avaliador. 


\begin{tabular}{|c|l|}
\hline Sujeitos & \multicolumn{1}{|c|}{ Resposta/Comentário } \\
\hline P1 & Um excelente material. \\
\hline $\mathbf{P 2}$ & $\begin{array}{l}\text { Gostei do material, a leitura fluiu bem, os termos foram explicados, não precisei recorrer } \\
\text { a outro recurso para compreender os termos mais especificos. A parte final colaborou para } \\
\text { ampliar o conhecimento de analogias para usar com meus alunos. }\end{array}$ \\
\hline $\mathbf{P 4}$ & $\begin{array}{l}\text { Achei o material bem completo e o tema abordado de suma importância. Este produto } \\
\text { auxilia o professor a refletir sobre o uso de analogias e, além disso, fornece vários } \\
\text { exemplos que podem ser utilizados. }\end{array}$ \\
\hline $\mathbf{P 5}$ & $\begin{array}{l}\text { É um material acessivel em termos de linguagem e conteúdo e com potencial para auxiliar } \\
\text { oprofessor no planejamento das aulas e na concretização do ensino-aprendizagem em sala } \\
\text { de aula. }\end{array}$ \\
\hline $\begin{array}{l}\text { É um material que só tem a contribuir com o ensino de Química, temática bastante } \\
\text { complexa e pouco discutida no âmbito da educação. }\end{array}$ \\
\hline
\end{tabular}

Quadro 05: respostas dos avaliadores à questão 5.

Fonte: elaboração dos autores (2020).

Os avaliadores fizeram comentários positivos em relação ao conteúdo, a escrita e a linguagem utilizada, as quais contribuíram para fluidez da leitura. De fato, na elaboração houve a preocupação de sistematizar um material dinâmico, atrativo e de leitura agradável, pode-se dizer que esses aspectos foram alcançados com sucesso.

Por fim, o avaliador poderia deixar comentários, sugestões ou críticas ao Guia Didático. Nos comentários foram unânimes os elogios: Parabéns pelo excelente trabalho (P2). Excelente contribuição para o ensino de Química (P6). O material está excelente e será muito útil na formação dos professores (P4). O material está completo! (P5). No que concerne às sugestões ou críticas, foram citados os seguintes apontamentos: erros de digitação; mencionar a figura 3 no texto; e colocar os recuos nas primeiras linhas dos parágrafos. Após a avaliação, o material passou novamente pela correção de Língua Portuguesa, de modo a eximir possíveis erros deixados após a diagramação. Todos esses apontamentos foram relevantes e inclusos na versão final do Guia Didático.

A partir dos resultados expostos foi possível inferir que o Guia Didático denominado Química com analogias: guia didático com orientações para o uso de analogias no Ensino de Química se mostrou, em uma primeira avaliação, um produto didático útil e viável, e que poderá auxiliar os professores no uso de analogias, de forma efetiva, em suas aulas. Assim, o objetivo proposto para o material foi alcançado de maneira assertiva.

\section{CONSIDERAÇÕES}

Trabalhar os conceitos a partir de elementos familiares aos estudantes é um estímulo importante para a aprendizagem de conceitos científicos que, na maioria das vezes, são distantes do seu cotidiano. Dessa forma, para que o Ensino de Ciências seja atrativo e que motive os 
estudantes a se envolverem, cognitivamente, com os conteúdos e com as discussões, em sala de aula, é necessário que o professor utilize uma linguagem mais acessível.

Uma das possibilidades é o uso de analogias, uma vez que essas aproximam os conceitos (alvo e análogo) de modo a tornar a aprendizagem mais plausível. Contudo, a condição inicial para o uso efetivo das analogias necessita ser a modificação da prática docente, por meio da reflexão e planejamento, quanto ao uso desse recurso didático.

Assim, ao ter conhecimentos relacionados ao uso das analogias, os professores estarão aptos para incluí-las em seu planejamento, bem como utilizá-las, de forma estruturada, contribuindo para que seu uso contemple a sua função, a de facilitar a compreensão de assuntos abstratos, a partir do que é familiar aos estudantes.

A partir da análise da avaliação do Guia Didático feita sob a ótica dos sujeitos foi possível validar a aplicabilidade do material, visto que este apresentou resultados satisfatórios e todos os sujeitos o aprovaram, em especial, quando informaram que sua utilização seria viável no planejamento de suas aulas, por ser um material que pode contribuir para diminuição dos obstáculos à aprendizagem, ao trabalhar com analogias em suas aulas. Assim, se concebe que o objetivo desta pesquisa foi alcançado e a pergunta de pesquisa respondida de maneira assertiva.

Estima-se que as informações propostas, neste Guia Didático, possam apoiar o trabalho dos professores de Ciências, em especial os de Química, no ensino de conteúdo para os quais possa ser utilizado tal recurso, para que ocorra sua compreensão. Importante destacar que a presente proposta não se reduz à aplicação mecânica de procedimentos e métodos, mas confere ao professor a liberdade de adequar o caminhar metodológico no sentido de promover a construção do conhecimento por parte dos estudantes.

Para concluir esta investigação, deixa-se o convite, aos pesquisadores e professores, para a elaboração de novas propostas didáticas que envolvam o uso de analogias como estratégia de ensino, pois se acredita na importância e na necessidade de investigações que abordam essa temática no Ensino de Ciências.

\section{REFERÊNCIAS}

ALMEIDA, G. M. A. Jogo digital e analogias: uma proposta para o ensino de Cinética Química 85 f. (Mestrado em Educação Para A Ciência) Universidade Est. Paulista Júlio De Mesquita Filho, 2015. Disponível em: https://repositorio.unesp.br/handle/11449/132517 Acesso em: 20 nov. 2020. 
BOGDAN, R.; BIKLEN, S. Investigação qualitativa em educação: uma introdução à teoria e aos métodos. Porto editora, 1994.

CRESWELL, J. W. W. Projeto de pesquisa: métodos qualitativo, quantitativo e misto. 2. ed. Porto Alegre: Bookman, 2010.

DUARTE, M. C. Analogias na Educação em ciências contributos e desafios. Revista Investigações em Educação de Ciências, 10, 1, 7-29, 2005. Disponível em:

https://www.if.ufrgs.br/cref/ojs/index.php/ienci/article/view/520/317. Acesso em: 10 out. 2020.

FERRAZ, D. F. O uso de analogias como recurso didático por professores e biologia no Ensino Médio. Cascavel: edunioeste, 2006.

FERRAZ, D. F.; TERRAZZAN, E. A O uso espontâneo de analogias por professores de Biologia: observações da prática pedagógica. Ensaio: Pesquisa em Educação em Ciências. Belo Horizonte: Cemicig; FAE, v. 4, n. 2, dez. 2002. Disponível em:

https://www.scielo.br/pdf/epec/v4n2/1983-2117-epec-4-02-00115.pdf. Acesso em: 10 out. 2020.

FRANCISCO JÚNIOR, W. E. Analogias e situações problematizadoras em aulas de Ciências. São Carlos: Pedro e João editores 2010.

LACERDA, A. G.; BRITO, M. M. Análise de livros didáticos de ciências a partir do uso de analogias: obstáculos e abordagens sobre o conteúdo célula. REAMEC-Rede Amazônica de Educação em Ciências e Matemática, v. 7, n. 2, p. 164-184, 2019. DOI:

10.26571/REAMEC.a2019. Disponível em:

https://periodicoscientificos.ufmt.br/ojs/index.php/reamec/article/view/8450. Acesso em: 22 out. 2020.

MORAES, R.; GALIAZZI, M. C. Análise Textual Discursiva. Ijuí: Ed. Unijuí, 2011.

MOZZER, N. B.; JUSTI, R. A elaboração de analogias como um processo que favorece a expressão de concepções de professores de química. Educación química, v. 24, p. 163-173, 2013. Disponível em:

https://www.sciencedirect.com/science/article/pii/S0187893X13725102. Acesso em: 22 out. de 2020 .

OLIVA, J. M. Qué conocimientos profesionales deberíamos tener los profesores de ciencias sobre el uso de analogías. Revista Eureka sobre Enseñanza y Divulgación de las Ciencias, v. 5, n. 1, p. 15-28, 2008. Disponível em:

https://revistas.uca.es/index.php/eureka/article/view/3770. Acesso em: 03 nov. de 2020.

QUEIROZ, R. O. A Atualização De Modelos Didáticos, Na Forma De Analogias, No Ensino De Isomeria 3d: Uma Investigação Dos Saberes Docentes Junto A Professores De Química. 109 f. Mestrado em Ensino Das Ciências Instituição De Ensino: Universidade Federal Rural De Pernambuco, Recife, 2015. Disponível em:

http://www.tede2.ufrpe.br:8080/tede2/handle/tede2/5960. Acesso em: 20 nov. 2020. 
RIGOLON, R. G. O conceito e o uso de analogias como recurso didático por licenciandos de Biologia, 132 f. Dissertação (Mestrado em Educação para as Ciências e o Ensino de Matemática) -Universidade Estadual de Maringá, Maringá, 2008. Disponível em: http://repositorio.uem.br:8080/jspui/handle/1/4467. Acesso em: 15 nov. 2020.

VASCONCELOS, M. A. M. Guia didático: proposta pedagógica e aprendizagens. Faculdades Integradas-ICE: Cuiabá, 2011.

YIN, R. K. Estudo de Caso: planejamento e métodos. 4.ed. Tradução Daniel Grassi. Porto Alegre: Bookman, 2015.

\section{NOTAS}

\section{AGRADECIMENTOS}

A todos os professores participantes desta pesquisa.

FINANCIAMENTO

Financiado pelo(s) próprio(s) autor(es).

\section{CONTRIBUIÇÕES DE AUTORIA}

Resumo/Abstract/Resumen: Rosiane Alexandre Pena Guimarães e Marcel Thiago Damasceno Ribeiro Introdução: Rosiane Alexandre Pena Guimarães e Marcel Thiago Damasceno Ribeiro Referencial teórico: Rosiane Alexandre Pena Guimarães e Marcel Thiago Damasceno Ribeiro Análise de dados: Rosiane Alexandre Pena Guimarães e Marcel Thiago Damasceno Ribeiro Discussão dos resultados: Rosiane Alexandre Pena Guimarães e Marcel Thiago Damasceno Ribeiro Conclusão e considerações finais: Rosiane Alexandre Pena Guimarães e Marcel Thiago Damasceno Ribeiro Referências: Rosiane Alexandre Pena Guimarães e Marcel Thiago Damasceno Ribeiro Revisão do manuscrito: Karin Elizabeth Rees de Azevedo Aprovação da versão final publicada: Rosiane Alexandre Pena Guimarães e Marcel Thiago Damasceno Ribeiro

\section{CONFLITOS DE INTERESSE}

Os autores declararam não haver nenhum conflito de interesse de ordem pessoal, comercial, acadêmico, político e financeiro referente a este manuscrito.

\section{DISPONIBILIDADE DE DADOS DE PESQUISA}

O conjunto de dados que dá suporte aos resultados da pesquisa foi publicado no próprio artigo.

\section{CONSENTIMENTO DE USO DE IMAGEM}

Não se aplica.

\section{APROVAÇ̃̃O DE COMITÊ DE ÉTICA EM PESQUISA}

Este estudo foi registrado e aprovado no Comitê de Ética de Pesquisa (CEP) Humanidades da Universidade Federal de Mato Grosso, no ano de 2020, sob o registro no CAAE: 26027219.2.0000.5690.

\section{COMO CITAR - ABNT}

GUIMARÃES, Rosiane Alexandre Pena; RIBEIRO, Marcel Thiago Damasceno. Química com analogias: o estudo da viabilidade de um guia didático, a partir de reflexões docentes. REAMEC - Rede Amazônica de Educação em Ciências e Matemática. Cuiabá, v. 9, n. 1, e21012, janeiro-abril, 2021. DOI: 10.26571/reamec.v9i1.11565.

\section{COMO CITAR - APA}

GUIMARÃES, R. A. P., \& RIBEIRO, M. T. D. (2021). Química com analogias: o estudo da viabilidade de um guia didático, a partir de reflexões docentes. REAMEC - Rede Amazônica de Educação em Ciências e Matemática, 9 (1), e21012. DOI: 10.26571/reamec.v9i1.11565. 


\section{LICENCA DE USO}

Licenciado sob a Licença Creative Commons Attribution-NonCommercial 4.0 International (CC BY-NC 4.0). Esta licença permite compartilhar, copiar, redistribuir o manuscrito em qualquer meio ou formato. Além disso, permite adaptar, remixar, transformar e construir sobre o material, desde que seja atribuído o devido crédito de autoria e publicação inicial neste periódico.

\section{DIREITOS AUTORAIS}

Os direitos autorais são mantidos pelos autores, os quais concedem à Revista REAMEC - Rede Amazônica de Educação em Ciências e Matemática - os direitos exclusivos de primeira publicação. Os autores não serão remunerados pela publicação de trabalhos neste periódico. Os autores têm autorização para assumir contratos adicionais separadamente, para distribuição não exclusiva da versão do trabalho publicada neste periódico (ex.: publicar em repositório institucional, em site pessoal, publicar uma tradução, ou como capítulo de livro), com reconhecimento de autoria e publicação inicial neste periódico. Os editores da Revista têm o direito de proceder a ajustes textuais e de adequação às normas da publicação.

\section{PUBLISHER}

Universidade Federal de Mato Grosso. Programa de Pós-graduação em Educação em Ciências e Matemática (PPGECEM) da Rede Amazônica de Educação em Ciências e Matemática (REAMEC). Publicação no Portal de Periódicos UFMT. As ideias expressadas neste artigo são de responsabilidade de seus autores, não representando, necessariamente, a opinião dos editores ou da referida universidade.

\section{EDITOR}

Dailson Evangelista Costa

\section{HISTÓRICO}

Submetido: 21 de dezembro de 2020.

Aprovado: 12 de janeiro de 2021.

Publicado: 22 de janeiro de 2021. 